University of Nebraska - Lincoln

DigitalCommons@University of Nebraska - Lincoln

8-1-2006

\title{
National Pork Producers Council Maternal Line National Genetic Evaluation Program: A comparison of sow longevity and trait associations with sow longevity
}

\author{
T. Serenius \\ lowa State University \\ K. J. Stalder \\ lowa State University, stalder@iastate.edu \\ T. J. Baas \\ lowa State University \\ J. W. Mabry \\ University of Nebraska-Lincoln \\ R. N. Goodwin \\ National Pork Board, Des Moines, IA \\ See next page for additional authors \\ Follow this and additional works at: https://digitalcommons.unl.edu/animalscifacpub \\ Part of the Animal Sciences Commons
}

Serenius, T.; Stalder, K. J.; Baas, T. J.; Mabry, J. W.; Goodwin, R. N.; Johnson, R. K.; Robison, O. W.; Tokach, M.; and Miller, R. K., "National Pork Producers Council Maternal Line National Genetic Evaluation Program: A comparison of sow longevity and trait associations with sow longevity" (2006). Faculty Papers and Publications in Animal Science. 71.

https://digitalcommons.unl.edu/animalscifacpub/71

This Article is brought to you for free and open access by the Animal Science Department at DigitalCommons@University of Nebraska - Lincoln. It has been accepted for inclusion in Faculty Papers and Publications in Animal Science by an authorized administrator of DigitalCommons@University of Nebraska - Lincoln. 


\section{Authors}

T. Serenius, K. J. Stalder, T. J. Baas, J. W. Mabry, R. N. Goodwin, R. K. Johnson, O. W. Robison, M. Tokach, and R. K. Miller 


\title{
National Pork Producers Council Maternal Line National Genetic Evaluation Program: A comparison of sow longevity and trait associations with sow longevity ${ }^{1}$
}

\author{
T. Serenius, ${ }^{*}$ K. J. Stalder, ${ }^{2}$ T. J. Baas, ${ }^{*}$ J. W. Mabry, ${ }^{*}$ R. N. Goodwin, $\dagger$ R. K. Johnson, \\ O. W. Robison, $\S$ M. Tokach,\# and R. K. Miller \\ *Department of Animal Science, Iowa State University, Ames 50011; †National Pork Board, \\ Des Moines, IA 50325; †Department of Animal Science, University of Nebraska, Lincoln 68583; \\ $\S$ Department of Animal Science, North Carolina State University, Raleigh 27695; \\ \#Kansas State University, Manhattan, KS 66506; and ||Texas A\&M University, College Station, TX 77843
}

\begin{abstract}
Data from the National Pork Producers Council Maternal Line National Genetic Evaluation Program were used to compare longevity of sows from 6 commercial genetic lines and to estimate the phenotypic associations of sow longevity with gilt backfat thickness, ADG, age at first farrowing, litter size at first farrowing, litter weight at first farrowing, average feed intake during lactation, and average backfat loss during lactation. The lines evaluated were American Diamond Genetics, Danbred North America, Dekalb-Monsanto DK44, Dekalb-Monsanto GPK347, Newsham Hybrids, and National Swine Registry. The data set contained information from 3,251 gilts, of which $17 \%$ had censored longevity records (sows lived longer than 6 parities). The line comparison was carried out by analyzing all lines simultaneously. Because the survival distribution functions differed among genetic lines, later analyses were carried out separately for each genetic line. All analyses were based on the nonparametric proportional hazard (Cox model). DekalbMonsanto GPK347 sows had a lower risk of being culled
\end{abstract}

than sows from the other lines. Moreover, the shape of the survival distribution function of the Delkab-Monsanto GPK347 line was different from the other 5 lines. The Dekalb-Monsanto 347 line had lower culling rates because they had lower gilt reproductive failure before the first parity than gilts from the other lines. Within line, sows with lower feed intake and greater backfat loss during lactation had a shorter productive lifetime. Thus, producers should implement management practices having positive effects on sow lactation feed intake. Additionally, the swine genetics industry is challenged to simultaneously improve efficiency of gain of their terminal market pigs and to obtain high feed intake during lactation of their maternal lines for future improvement of sow longevity. Recording sow feed intake and backfat loss during lactation in nucleus and multiplication breeding herds should be considered. Between-line differences in this study indicate that it is possible to select for sow longevity, but more research is needed to determine the most efficient selection methods to improve sow longevity.

Key words: backfat thickness, feed intake, genetic line, sow longevity

(C)2006 American Society of Animal Science. All rights reserved.

J. Anim. Sci. 2006. 84:2590-2595

doi:10.2527/jas.2005-499

\section{INTRODUCTION}

Sow longevity plays an important role in economically efficient piglet production (Lacy and Stalder, 2004).

\footnotetext{
${ }^{1}$ This journal paper of the Iowa Agric. and Home Econ. Exp. Stn., Ames, IA, Project No. 3456, was supported by Hatch Act and State of Iowa funds. Additional funding and support was provided by the Academy of Finland (No. 212257).

${ }^{2}$ Corresponding author: stalder@iastate.edu

Received September 7, 2005.

Accepted May 1, 2006.
}

Moreover, heritability estimates indicate that genetic variation exists for sow longevity (Tholen et al., 1996; Yazdi, et al., 2000; Serenius and Stalder, 2004). Thus, one might expect that differences in sow longevity exist among lines available to commercial swine producers. However, comparison of commercial genetic lines has been almost impossible. As a result, limited information is available to producers to allow them to differentiate between genetic lines on the basis of sow longevity.

Reliable comparisons of genetic lines are possible only when environment and management practices are standardized or if parameters can be accurately estimated by appropriate mathematical modeling. The Maternal 
Line National Genetic Evaluation Program (MLP) was initiated to evaluate reproductive performance and sow longevity of 6 maternal lines available to US swine producers. The program was designed and conducted by the National Pork Producers Council (NPPC) Genetic Programs Committee (Des Moines, IA). A more complete description of the MLP study is presented in Moeller et al. (2004).

Rapid genetic improvement has been attained for production traits, such as daily gain, G:F, and backfat thickness during past decades. Simultaneously, there has been a decrease in sow longevity (Stalder et al., 2004). Thus, one might expect that these traits are unfavorably associated. To improve sow longevity, these associations should be known.

The objective of this study was to compare sow longevity of different genetic lines and to evaluate the phenotypic associations of sow longevity with gilt backfat thickness (at $100 \mathrm{~kg}$ ), $\mathrm{ADG}$ (from birth to $100 \mathrm{~kg}$ ), age at first farrowing, litter size at first farrowing, litter weight at first farrowing, average backfat loss during lactation, and average feed intake during lactation.

\section{MATERIALS AND METHODS}

Data in this study were obtained from the MLP conducted by NPPC. Six lines/suppliers included in the study were American Diamond Swine Genetics (Prairie City, IA), Danbred North America (DB; Seward, NE), Dekalb-Monsanto DK44 (St. Louis, MO), Dekalb-Monsanto GPK347 (GPK347; St. Louis, MO), Newsham Hybrids (NH; West Des Moines, IA), and National Swine Registry (NSR; West Lafayette, IN). The DB, DekalbMonsanto DK44, American Diamond Swine Genetics, and $\mathrm{NH}$ were maternal lines that were available to commercial producers.

These lines were made by crossing closed lines maintained by each organization to produce females that expressed 100\% maternal heterosis and thus were considered to be $\mathrm{F}_{1}$ females. Defining crossbreds that express $100 \%$ heterosis as $\mathrm{F}_{1}$ is consistent with several reports in the literature (Gregory and Cundiff, 1980; Gregory et al., 1991; Cassady et al., 2002). These lines consisted of animals with Landrace and Large White-Yorkshires origins in most cases but might have included introductions of other breeds during development of the line. The NSR line was $\mathrm{F}_{1}$ Yorkshire-Landrace crossbred gilt produced by crossing Landrace boars with Yorkshire gilts, or the reciprocal cross, or both, at purebred cooperator herds.

The GPK347 line was produced by inseminating $\mathrm{F}_{1}$ females of a cross of 2 Dekalb-Monsanto maternal lines with semen of boars from the Nebraska Index line. The Nebraska Index line was a composite of Large White and Landrace genetic origin that was selected for 16 generations for increased ovulation rate, embryonic survival, and litter size at birth at the University of Nebraska (NPPC, 2000). Because of the large number of generations separating the Nebraska Index line from the Dekalb-Monsanto lines and the unique selection in its development, the GPK347 line was also considered to be an $F_{1}$.

Sow longevity was determined as a length of productive life and calculated as a time from sow entry to the breeding herd to culling or censoring date. The data set contained performance information on 3,251 gilts, of which $17 \%$ had a right-censored longevity record (i.e., sows lived longer than 6 parities; Table 1). Of these gilts, $78.4 \%$ reached their first parity (i.e., $21.6 \%$ of the gilts never farrowed). For this reason, the analyses were carried out in 3 steps. First, line comparisons were made by fitting one baseline hazard function (line in the model) for all lines before examining line differences in longevity. Because the survival distribution functions differed between the genetic lines, this procedure can be considered ad-hoc. However, using this method we were able to determine if one of the genetic lines was superior for sow longevity.

After line comparison, the effects of gilt backfat thickness and ADG on sow longevity were estimated separately for each genetic line. Each genetic line was analyzed separately because the survival distribution functions differed among lines, especially between the GPK347 and the other lines studied (Figure 1). Additionally, associations between traits might differ among the genetic lines. For these 2 steps, longevity information was utilized from all the gilts, including the ones that never farrowed. Third, the effects of age at first farrowing, litter size at first farrowing, litter weight at first farrowing, backfat loss during last lactation, and feed intake during last lactation on sow longevity were studied in a way similar to the second approach, but the information was utilized only from sows that farrowed at least once.

Backfat loss during the last lactation before removal was scaled per day of lactation (cm/day), and feed intake during the last lactation was scaled per day of lactation and piglet $\left(\mathrm{kg} \cdot \mathrm{d}^{-1} \cdot\right.$ weaned piglet $\left.{ }^{-1}\right)$. Because feed intake during lactation is lower in the first compared with later lactations, it was adjusted to the fourth parity. The adjustment was implemented using least squares means of lactation feed intake of different parities, including number of piglets weaned in the statistical model. The least squares mean differences from the fourth parity were $1.66,0.59$, and $0.03 \mathrm{~kg} \cdot \mathrm{d}^{-1} \cdot$ weaned piglet ${ }^{-1}$ in first, second, and third parities, respectively. The same adjustment factors were used for all genetic lines. Similarly, ADG from birth to $100 \mathrm{~kg}$ and gilt backfat thickness at $100 \mathrm{~kg}$ were adjusted according to procedures recommended by the National Swine Improvement Federation (NSIF; NSIF, 1996).

All analyses were carried out by fitting the proportional nonparametric (Cox) model to the longevity records. The hazard function of a sow's length of productive life, $t$ days after the entrance into the breeding herd, can be written as:

$$
h(t)=h_{0}(t) e^{x^{\prime} b}
$$


Table 1. Number of animals, proportion of censored (sows living longer than 6 parities; censored, \%) sows, and culling/censoring ages for all gilts (gilt data) and only the sows that farrowed (sow data) in the National Pork Producers Council Maternal Line National Genetic Evaluation Program ${ }^{1}$

\begin{tabular}{lcccccc}
\hline \hline & NH & NSR & ADSG & DK44 & GPK347 & DB \\
\hline Gilt data & & & & & & \\
No. of gilts & 560 & 511 & 560 & 544 & 540 & 536 \\
Censored, \% & 14.3 & 16.6 & 15.4 & 16.0 & 25.4 & 12.3 \\
Average culling age, d & 463 & 447 & 456 & 441 & 531 & 448 \\
Average censoring age, d & 942 & 937 & 943 & 932 & 914.2 & 934 \\
Sow data & & & & & & \\
No. of sows & 436 & 376 & 430 & 405 & 494 & 408 \\
Censored, \% & 18.1 & 22.3 & 20.0 & 21.5 & 27.5 & 16.2 \\
Average culling age, d & 565 & 569 & 562 & 557 & 574 & 553 \\
Average censoring age, d & 942 & 938 & 943 & 932 & 914 & 934 \\
\hline
\end{tabular}

${ }^{1} \mathrm{NH}$ = Newsham Hybrids; NSR = National Swine Registry; ADSG = American Diamond Swine Genetics; DK44 = Dekalb-Monsanto DK44; GPK347 = Dekalb-Monsanto GPK347; and DB = Danbred North America.

where $h_{0}(t)$ is the nonparametric baseline hazard function, $\boldsymbol{b}$ is the vector of fixed effects, and $\boldsymbol{x}$ is the corresponding incidence matrix. All effects mentioned above, including the effect of breed in the first analysis, were included in $\boldsymbol{b}$. Effects of gilt backfat thickness, ADG, age at first farrowing, litter weight at first farrowing, backfat loss during last lactation, and feed intake during the last lactation were included as fixed regressions in $\boldsymbol{b}$, whereas litter size (small: $<9$ piglets; medium: 9 to 13 piglets; large: $>13$ piglets) in the first parity was in- cluded as a fixed effect. In addition, the effect of common contemporary group (sow unit + genetic line + entry day; see NPPC, 2000) was included in the vector $\boldsymbol{b}$. Statistical analyses were carried out with The Survival Kit package (Ducrocq and Sölkner, 2001).

\section{RESULTS}

Sows from the GPK347 line had lower risk of being culled than sows of the other lines evaluated in this

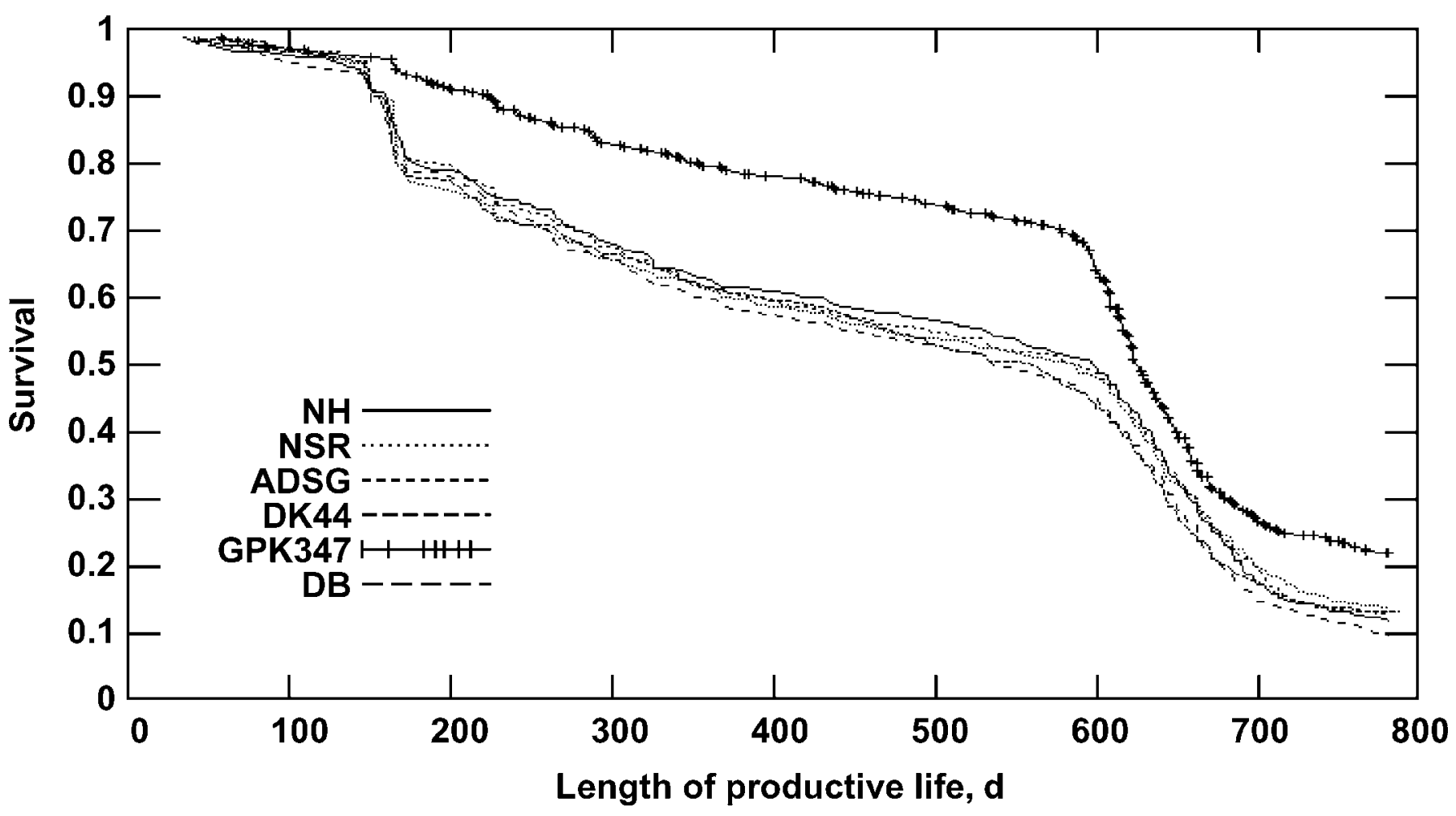

Figure 1. Survival distribution functions for genetic lines evaluated in the National Pork Producers Council's Maternal Line Genetic Evaluation Program. All the gilts were included in the data. The genetic lines evaluated were Newsham Hybrids (NH), National Swine Registry (NSR), American Diamond Swine Genetics (ADSG), DekalbMonsanto DK44 (DK44), Dekalb-Monsanto GPK347 (GPK347), and Danbred North America (DB). 
Table 2. Proportional risk of sows being culled (risk ratio) between 6 genetic lines evaluated in the National Pork Producers Council Maternal Line National Genetic Evaluation Program ${ }^{1,2}$

\begin{tabular}{llllccl}
\hline \hline Line & NH & NSR & ADSG & DK44 & GPK347 & DB \\
\hline NH & 1 & 1.03 & 1.02 & 0.97 & 1.41 & 0.92 \\
NSR & 0.97 & 1 & 0.99 & 0.94 & 1.37 & 0.89 \\
ADSG & 0.98 & 1.01 & 1 & 0.95 & 1.38 & 0.90 \\
DK44 & 1.04 & 1.06 & 1.06 & 1 & 1.46 & 0.95 \\
GPK347 & 0.71 & 0.73 & 0.72 & 0.69 & 1 & 0.65 \\
DB & 1.09 & 1.12 & 1.11 & 1.05 & 1.53 & 1 \\
\hline
\end{tabular}

${ }^{1} \mathrm{NH}=$ Newsham Hybrids; NSR = National Swine Registry; $\mathrm{ADSG}=$ American Diamond Swine Genetics; DK44 = Dekalb-Monsanto DK44; GPK347 = Dekalb-Monsanto GPK347; and DB = Danbred North America.

${ }^{2}$ Risk ratios are scaled proportional to each line (column) separately.

study (Table 2). For example, sows from the NSR line had 1.37 times greater risk of being culled than sows from the GPK347 line, the second most robust animals in the current comparison. The survival distribution functions (Figure 1) indicate that the greatest difference in sow removal occurred before first parity. Sows from the other 5 lines had difficulties in conceiving their first litter, whereas GPK347 sows did not demonstrate such difficulty. Differences in sow longevity of the other 5 lines in this environment were relatively low.

Estimates of hazard regression coefficients and proportions of the reduction of $R^{2}$ in reduced model out of the full model $R^{2}$ are presented in Tables 3 and 4 . Regression coefficients indicate the change in risk of sow being culled by 1 unit change in covariate variable. Proportions of $\mathrm{R}^{2}$ values indicate the importance of effect in the statistical model (i.e., if the ratio is 0 , the effect is not giving any extra information about risk of sow being culled).

When all gilts were included in the analysis, and only gilt backfat thickness and ADG were included in the statistical model for each genetic line separately, gilt backfat thickness significantly affected sow longevity, except in the GPK347 line (Table 3). Estimated hazard coefficients were negative for all the breeds (i.e., the greater the gilt backfat thickness, the lower the risk of sow being culled). When gilts that never farrowed were excluded from the data, gilt backfat thickness was not significantly associated with sow longevity in the GPK347, NH, and DB lines (Table 4).

Feed intake during lactation and backfat loss during lactation were factors associated with sow longevity for most breeds (Table 4). Feed intake during lactation had a significant effect on longevity for all lines, except for NH. Similarly, GPK347 and DB were lines that did not demonstrate a significant association between longevity and backfat loss during lactation. Generally, however, lower feed intake and greater backfat loss during lactation were associated with greater risks of sows being culled. Estimated hazard coefficients ranged from -1.40 to 0.05 per $\mathrm{kg} \cdot \mathrm{d}^{-1}$. piglet weaned ${ }^{-1}$ for feed intake, and from 2.96 to 13.31 per $\mathrm{cm}$ in backfat loss during lactation.

Age at first farrowing in DB line females and litter size at first farrowing in DB and GPK347 line females were significantly associated with sow longevity (Table 4). Greater age at first farrowing increased the risk of being culled in the DB line. Intermediate litter sizes showed the lowest risk of sows being culled, with the relative risks being 1.6, 1.0, and 1.0 in GPK347, and 1.3, 1.0, and 1.4 in the DB line for small (under 9 piglets born), medium (between 9 and 13 piglets born), and large litters (over 13 piglets born), respectively (data not shown).

Although associations between the most significant effects were of the same magnitude among the genetic lines, associations between various factors evaluated and longevity were significant for some lines whereas in other lines the associations of the same factors were not statistically significant (Tables 3 and 4). The same types of differing associations occurred when evaluating full and reduced data sets for the associations of sow longevity with gilt backfat thickness and ADG.

\section{DISCUSSION}

The current study was conducted to examine differences in sow longevity among genetic lines and to determine the phenotypic associations of certain economically

Table 3. Estimates of hazard regression coefficients $(b)$ on risk of culling on a given day and percentages of reduction of $\mathrm{R}^{2}(\%)$ in a reduced model (effect is not included in the model) compared with the full model for statistical analysis of sow longevity in each of 6 lines from the National Pork Producers Council Maternal Line National Genetic Evaluation Program ${ }^{1,2}$

\begin{tabular}{|c|c|c|c|c|c|c|c|c|c|c|c|c|}
\hline Trait $^{3}$ & \multicolumn{2}{|c|}{$\mathrm{NH}$} & \multicolumn{2}{|c|}{ NSR } & \multicolumn{2}{|c|}{$\mathrm{ADSG}$} & \multicolumn{2}{|c|}{ DK44 } & \multicolumn{2}{|c|}{ GPK347 } & \multicolumn{2}{|c|}{ DB } \\
\hline GiltBF, cm & $-0.39^{* *}$ & 22.5 & $-0.57 * *$ & 50.9 & $-0.34^{* *}$ & 30.9 & $-0.62^{* *}$ & 37.4 & -0.07 & 0.8 & $-0.49^{* *}$ & 21.8 \\
\hline
\end{tabular}

\footnotetext{
$\dagger P<0.10 ; * P<0.05 ; * * P<0.01$.

${ }^{1}$ All of the gilts were included in the survival analysis.

${ }^{2} \mathrm{NH}=$ Newsham Hybrids; NSR = National Swine Registry; ADSG = American Diamond Swine Genetics; DK44 = Dekalb-Monsanto DK44; GPK347 = Dekalb-Monsanto GPK347; and DB = Danbred North America.

${ }^{3} \mathrm{GiltBF}=$ gilt backfat thickness at $100 \mathrm{~kg} ; \mathrm{ADG}=$ average daily gain from birth to $100 \mathrm{~kg}$.
} 
Table 4. Estimates of hazard regression coefficients $(b)$ on risk of culling on a given day and percentages of reduction of $R^{2}(\%)$ in a reduced model (effect is not included in the model) compared with the full model for statistical analysis of sow longevity in each of 6 lines from the National Pork Producers Council Maternal Line National Genetic Evaluation Program ${ }^{1,2}$

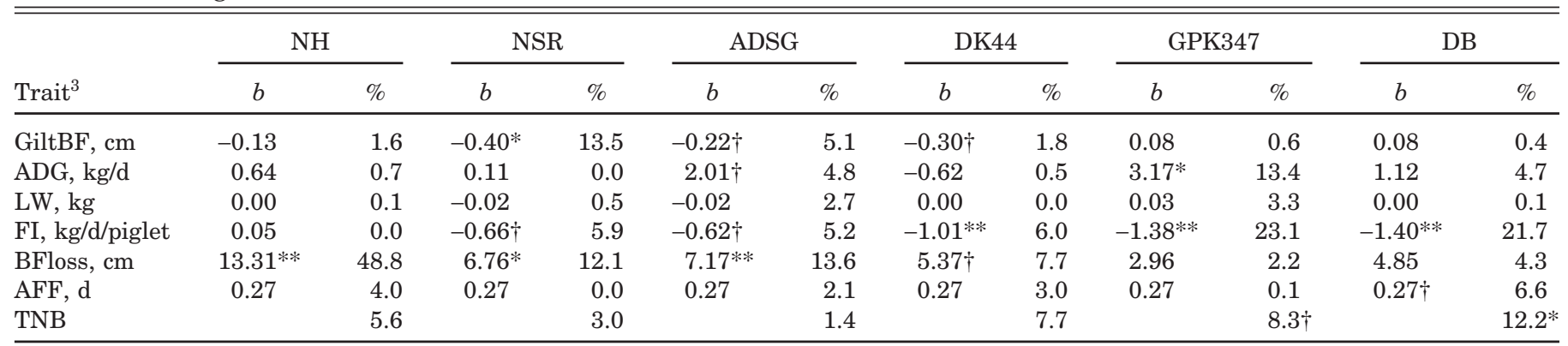

$\dagger P<0.10 ; * P<0.05 ; * * P<0.01$ denote factors significantly associated (differed from zero) with the length of productive life within line.

${ }^{1}$ Only sows that farrowed at least once were included in the survival analysis.

${ }^{2} \mathrm{NH}=$ Newsham Hybrids; NSR = National Swine Registry; ADSG = American Diamond Swine Genetics; DK44 = Dekalb-Monsanto DK44; GPK347 = Dekalb-Monsanto GPK347; and DB = Danbred North America.

${ }^{3}$ GiltBF = gilt backfat thickness at $100 \mathrm{~kg} ; \mathrm{ADG}=$ average daily gain from birth to $100 \mathrm{~kg} ; \mathrm{LW}=$ litter weight at birth; FI = feed intake during lactation; BFloss = backfat loss during lactation; AFF = age at first farrowing; TNB = total number of piglets born.

important performance traits with sow longevity. These objectives were achieved by analyzing data obtained from the MLP, a highly appropriate data set for the objective because no culling due to poor production was allowed until a sow had reached the fourth parity. Thus, associations observed between length of productive life and other traits studied were not affected by selection on performance traits or by sow culling policies associated with reproduction. Moreover, unique variables not normally available in field data but often thought to be related to longevity, including lactation feed intake and backfat loss during lactation were available.

\section{Line Comparison}

The GPK347 sows had clearly lower risk of being culled than sows of all other lines studied Differences among the other 5 lines were relatively small. As there is no detailed description about the breeding programs of these lines available in the literature, it is difficult to determine precise reasons for the superiority in sow longevity demonstrated by GPK347 sows. However, GPK347 is known as a line made up of half of the Nebraska selection line that was selected only for sow productivity traits, specifically ovulation rate, embryonic survival, and litter size at birth (Neal et al., 1989; Johnson et al., 1999), which may explain its superiority, at least in part. This selection may have elicited a positive response in longevity due to favorable genetic correlations, or the superiority may have existed in the base population and been maintained because no selection for increased growth or decreased fat had occurred. These possible explanations are in agreement with unfavorable genetic associations that were found between backfat thickness and longevity in the Finnish Large White population (Serenius and Stalder, 2004). Moreover, Cassady et al. (2004) found that offspring of GPK347 sows grew slower and had poorer carcass composition than offspring from the other 5 lines studied. In other words, because the GPK347 line has not been highly selected for meat production and growth traits, the unfavorable genetic correlations had not negatively impacted the genetic gain obtained in prolificacy and longevity.

Although the GPK347 line is superior in sow longevity and piglet production (Moeller et al., 2004), it should be remembered that they are not necessarily the most profitable sows in all commercial production systems. Because pigs produced by GPK347 sows grew slower and had poorer carcass composition (Cassady, et al., 2004), the total economic impact on pork production must be considered when commercial pork producers are evaluating the use of these females in their operations. Thus, although there is now information available comparing the production prolificacy and sow longevity of different genetic lines, pork producers need to evaluate the results on an individual basis. Economic values differ among production systems, and thus, the ranking of most profitable genetic lines may also differ among pork operations.

\section{Traits Affecting Sow Longevity}

In the literature, most studies evaluating sow longevity in commercial herds have concluded that litter size is positively associated with sow longevity (Tholen et al., 1996; Yazdi, et al., 2000; Serenius and Stalder, 2004). However, that conclusion is not supported by the current results. This is most likely due to the fact that culling of sows due to poor production was not allowed before the fourth parity in the current study. Such culling is common in commercial herds. The association between litter size and sow longevity can be, at least partly, explained by the autocorrelation, i.e., when sows are culled because of small litters, they will automatically have a relatively lower length of productive life.

It should be noted that gilt backfat thickness was significantly associated with sow longevity in all the genetic lines, except GPK347, when the analysis con- 
tained all gilts. However, the association was not as strong when gilts that never farrowed were excluded from the data set. It may indicate that gilt backfat level affects whether gilts successfully conceive and farrow their first litter, whereas the association between backfat and sow longevity is not as strong for sows that successfully complete their first parity. Yazdi et al. (2000) did not find significant associations between gilts' side backfat measured at field performance test and length of productive lifetime recorded after first farrowing. However, López-Serrano et al. (2000) found both $\mathrm{ADG}$ and backfat thickness to be genetically unfavorably correlated with sow stayability. Thus, associations seem to depend on the populations being studied. The consistent associations between gilt backfat thickness and sow longevity estimated using all data raises a question of whether some kind of threshold value may exist for backfat thickness that affect or determine whether a gilt will successfully produce her first litter. More research is needed to determine if nonlinear relationships between sow longevity and the other traits studied do in fact exist.

Based on current results, feed intake and backfat loss during lactation are the factors having the greatest association with sow longevity. Because selection for low feed intake or superior feed conversion ratio ( $\mathrm{kg}$ of meat $/ \mathrm{kg}$ of feed) has been practiced for many generations in most breeding programs, the association is unfavorable, at least from the breeding perspective. In other words, if the genetic correlation is similar to the phenotypic one, a challenge exists to select pigs that utilize feed more efficiently without decreasing or depressing the animal's appetite. Moreover, this result indicates the importance of having highly palatable feed available, feeder management, and other management factors designed to increase sow feed intake during lactation.

Although feed intake and backfat loss during lactation were significantly associated with sow longevity, one cannot be sure that selection for appetite will necessarily be beneficial for sow longevity. It may be that poor appetite is a secondary reason for other problems that lead to sow culling. Thus, more research is needed to study the genetic association between feed intake and sow longevity. If a genetic association between feed intake and sow longevity exists, the swine breeding industry should consider recording these traits for use in selection programs. It may be possible to select simultaneously for low backfat thickness and feed intake in market pigs during the weaning to slaughter period, and for low backfat loss and high feed intake in sows during lactation.

\section{IMPLICATIONS}

Differences in sow longevity between genetic lines exist. Thus, pork producers have the opportunity to select lines superior for sow longevity based on scientific comparisons. Moreover, the current results indicate that gilt backfat thickness is a critical factor in determining whether a gilt will successfully farrow her first litter and to some extent on later sow longevity. However, feed intake and backfat loss during lactation are primary factors associated with sow longevity once gilts have successfully produced a litter. Thus, producers should focus on management practices having positive effects on sow appetite to ensure the greatest length of productive life. Additionally, the breeding industry should consider recording feed intake and backfat loss during lactation for sows in nucleus and multiplication herds.

\section{LITERATURE CITED}

Cassady, J. P., O. W. Robison, R. K. Johnson, J. W. Mabry, L. L. Christian, M. D. Tokach, R. K. Miller, and R. N. Goodwin. 2004. National Pork Producers Council Maternal Line Genetic Evaluation: A comparison of growth and carcass traits in terminal progeny. J. Anim. Sci. 82:3482-3485.

Cassady, J. P., L. D. Young, and K. A. Leymaster. 2002. Heterosis and recombination effects on pig reproductive traits. J. Anim. Sci. 80:2303-2315.

Ducrocq, V., and J. Sölkner. 2001. The Survival Kit V3.12. User's Manual. Available: http://www-sgqa.jouy.inra.fr/diffusions.htm Accessed Apr. 4, 2005.

Gregory, K. E., and L. V. Cundiff. 1980. Crossbreeding in beef cattle: Evaluation of systems. J. Anim. Sci. 51:1224-1242.

Gregory, K. E., L. V. Cundiff, and R. M. Koch. 1991. Breed effects and heterosis in advanced generations of composite populations for preweaning traits of beef cattle. J. Anim. Sci. 69:947-960.

Johnson, R. K., M. K. Nielsen, and D. S. Casey. 1999. Responses in ovulation rate, embryonal survival, and litter traits in pigs to 14 generations of selection to increase litter size. J. Anim. Sci. 77:541-557.

Lacy, R. C., and K. J. Stalder. 2004. Sow Longevity Calculator Ver. 2.0: Farrow-to-Finish. Metric and English unit measures. Available: http://www.extension.iastate.edu/ipic/information/FFSLv2.html Accessed Apr. 4, 2005.

López-Serrano, M., N. Reinsch, H. Looft, and E. Kalm. 2000. Genetic correlations of growth, backfat thickness and exterior with stayability in large white and landrace sows. Livest. Prod. Sci. 64:121-131.

Moeller, S. J., R. N. Goodwin, R. K. Johnson, J. W. Mabry, T. J. Baas, and O. W. Robison. 2004. The National Pork Producers Council Maternal Line National Genetic Evaluation Program: A comparison of six maternal genetic lines for female productivity measures over four parities. J. Anim. Sci. 82:41-53.

Neal, S. M., R. K. Johnson, and R. J. Kittok. 1989. Index selection for components of litter size in swine: Response to five generations of selection. J. Anim. Sci. 67:1939-1945.

NPPC. 2000. National Pork Producers Council. Maternal Line National Genetic Evaluation Program Results. R. N. Goodwin, ed. Natl. Pork Producers Counc., Clive, IA.

NSIF. 1996. Guidelines for Uniform Swine Improvement Programs. National Swine Improvement Federation. Available: http:// www.nsif.com/ Accessed Feb. 17, 2005.

Serenius, T., and K. J. Stalder. 2004. Genetics of length of productive life and lifetime prolificacy in the Finnish Landrace and Large White populations. J. Anim. Sci. 82:3111-3117.

Stalder, K. J., M. Knauer, T. J. Baas, M. F. Rothschild, and W. Mabry. 2004. Sow longevity. Pig News Inf. 25:53-74.

Tholen, E., K. L. Bunter, S. Hermesch, and H.-U. Graser. 1996. The genetic foundation of fitness and reproduction traits in Australian pig populations 1. Genetic parameters for weaning to conception interval, farrowing interval, and stayability. Aust. J. Agric. Res. 47:1261-1274.

Yazdi, M., L. Rydhmer, E. Ringmar-Cederberg, N. Lundeheim, and K. Johansson. 2000. Genetic study of longevity in Swedish Landrace sows. Livest. Prod. Sci. 63:255-264. 